NASA/CR-2000-209809

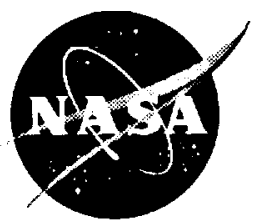

Design, Fabrication, and Testing of Ceramic Joints for High Temperature $\mathrm{SiC} / \mathrm{SiC}$ Composites

Mrityunjay Singh

Dynacs Engineering Company, Inc., Brook Park, Ohio

Edgar Lara-Curzio

Oak Ridge National Laboratory, Oak Ridge, Tennessee 
Since its founding, NASA has been dedicated to the advancement of aeronautics and space science. The NASA Scientific and Technical Information (STI) Program Office plays a key part in helping NASA maintain this important role.

The NASA STI Program Office is operated by Langley Research Center, the Lead Center for NASA's scientific and technical information. The NASA STI Program Office provides access to the NASA STI Database, the largest collection of aeronautical and space science STI in the world. The Program Office is also NASA's institutional mechanism for disseminating the results of its research and development activities. These results are published by NASA in the NASA STI Report Series, which includes the following report types:

- TECHNICAL PUBLICATION. Reports of completed research or a major significant phase of research that present the results of NASA programs and include extensive data or theoretical analysis. Includes compilations of significant scientific and technical data and information deemed to be of continuing reference value. NASA's counterpart of peerreviewed formal professional papers but has less stringent limitations on manuscript length and extent of graphic presentations.

- TECHNICAL MEMORANDUM. Scientific and technical findings that are preliminary or of specialized interest, e.g., quick release reports, working papers, and bibliographies that contain minimal annotation. Does not contain extensive analysis.

- CONTRACTOR REPORT. Scientific and technical findings by NASA-sponsored contractors and grantees.
- CONFERENCE PUBLICATION. Collected papers from scientific and technical conferences, symposia, seminars, or other meetings sponsored or cosponsored by NASA.

- SPECIAL PUBLICATION. Scientific, technical, or historical information from NASA programs, projects, and missions, often concerned with subjects having substantial public interest.

- TECHNICAL TRANSLATION. Englishlanguage translations of foreign scientific and technical material pertinent to NASA's mission.

Specialized services that complement the STI Program Office's diverse offerings include creating custom thesauri, building customized data bases, organizing and publishing research results ... even providing videos.

For more information about the NASA STI Program Office, see the following:

- Access the NASA STI Program Home Page at http://www.sti.nasa.gov

- E-mail your question via the Internet to help@sti.nasa.gov

- Fax your question to the NASA Access Help Desk at (301) 621-0134

- Telephone the NASA Access Help Desk at (301) 621-0390

- Write to: NASA Access Help Desk NASA Center for AeroSpace Information 7121 Standard Drive Hanover, MD 21076 
NASA/CR-2000-209809

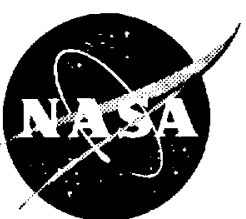

\section{Design, Fabrication, and Testing of Ceramic Joints for High Temperature $\mathrm{SiC} / \mathrm{SiC}$ Composites}

Mrityunjay Singh

Dynacs Engineering Company, Inc., Brook Park, Ohio

Edgar Lara-Curzio

Oak Ridge National Laboratory, Oak Ridge, Tennessee

Prepared for the

45th International Gas Turbine and Aeroengine Technical Congress sponsored by the American Society of Mechancial Engineers

Munich, Germany, May 8-11, 2000

Prepared under Contract NAS3-98008

National Aeronautics and

Space Administration

Glenn Research Center 


\section{Acknowledgments}

The authors would like to thank Mr. R.F. Dacek for his help in the preparation of specimens. The research activities carried out at ORNL were sponsored by the U.S. Department of Energy, Assistant Secretary for Energy Efficiency and Renewable Energy, Office of Industrial Technologies, Industrial Energy Efficiency Division and

Continuous Fiber Ceramic Composites Program, under contract DE-AC05-96OR22464 with Lockheed Martin Energy Research Corporation.

Trade names or manufacturers' names are used in this report for identification only. This usage does not constitute an official endorsement, either expressed or implied, by the National Aeronautics and Space Administration.

Available from

NASA Center for Aerospace Information

7121 Standard Drive

Hanover, MD 21076

Price Code: A03
National Technical Information Service 5285 Port Royal Road Springfield, VA 22100

Price Code: A03 


\title{
DESIGN, FABRICATION, AND TESTING OF CERAMIC JOINTS FOR HIGH TEMPERATURE SiC/SiC COMPOSITES
}

\author{
Mrityunjay Singh \\ Dynacs Engineering Company, Inc. \\ 2001 Aerospace Parkway \\ Brook Park, Ohio 44142 \\ Edgar Lara-Curzio \\ Oak Ridge National Laboratory \\ Metals and Ceramics Division \\ Oak Ridge, Tennessee 37831
}

\begin{abstract}
SUMMARY
Various issues associated with the design and mechanical evaluation of joints of ceramic matrix composites are discussed. The specific case of an affordable, robust ceramic joining technology (ARCJoinT) to join silicon carbide (CG-Nicalon ${ }^{\mathrm{TM}}$ ) fiber-reinforced-chemically vapor infiltrated (CVI) silicon carbide matrix composites is addressed. Experimental results are presented for the time and temperature dependence of the shear strength of these joints in air up to $1200^{\circ} \mathrm{C}$. From compression testing of double-notched joint specimens with a notch separation of $4 \mathrm{~mm}$, it was found that the apparent shear strength of the joints decreased from $92 \mathrm{MPa}$ at room temperature to $71 \mathrm{MPa}$ at $1200{ }^{\circ} \mathrm{C}$. From shear stress-rupture testing in air at $1200^{\circ} \mathrm{C}$ it was found that the shear strength of the joints decreased rapidly with time from an initial shear strength of 71 to $17.5 \mathrm{MPa}$ after $14.3 \mathrm{hr}$. The implications of these results in relation to the expected long-term service life of these joints in applications at elevated temperatures are discussed.
\end{abstract}

\section{INTRODUCTION}

Ceramic matrix composites (CMCs) are leading candidate materials for a wide variety of high temperature, high performance aerospace and land-based applications. The potential applications of CMCs in the aerospace industry include combustor liners, exhaust nozzles, and a number of other aircraft gas turbine and space propulsion components. The land-based applications of these materials include radiant burners, hot gas filters, high-pressure heat exchanger tubes, and combustor liners in industrial gas turbine engines. In addition, there are a number of potential uses of CMCs for the first wall and blanket components of nuclear fusion reactors.

At present, most approaches for the fabrication of ceramic matrix composites (CMCs) are based on the gas or liquid infiltration of the ceramic matrix into a ceramic fiber preform. Among the various technologies available for the manufacturing of CMCs, chemical vapor infiltration (CVI) is the most mature and most widely used. However, the main drawbacks of this process are the: (1) difficulty in achieving uniform and complete densification of large and/or geometrically-complex shaped components, and (2) lengthy processing time. Therefore, design considerations for the manufacture of large CVI ceramic matrix composite components and structures are being based on using technologies for joining/attaching smaller-sized components with simpler geometry. Thus, ceramic joining is today recognized as an enabling technology for the successful implementation of CMCs in some of the aforementioned applications (refs. 1 to 4).

Various joint design issues are discussed in this paper and the particular case of joints of silicon carbide (CG-Nicalon ${ }^{\mathrm{TM}}$ ) fiber-reinforced CVI-SiC composites is addressed. These joints were produced using the affordable, robust ceramic joining technology (ARCJoinT) (refs. 5 to 12). This technique is based on the reaction forming approach and will be described and discussed in terms of global design considerations. This joining technology is unique in terms of producing joints with tailorable microstructures. The formation of joints by this approach is attractive since the thermomechanical properties of the joint interlayer can be tailored to be very close to those of the base materials. In addition, high temperature fixturing is not needed to hold the parts at the infiltration temperature. 


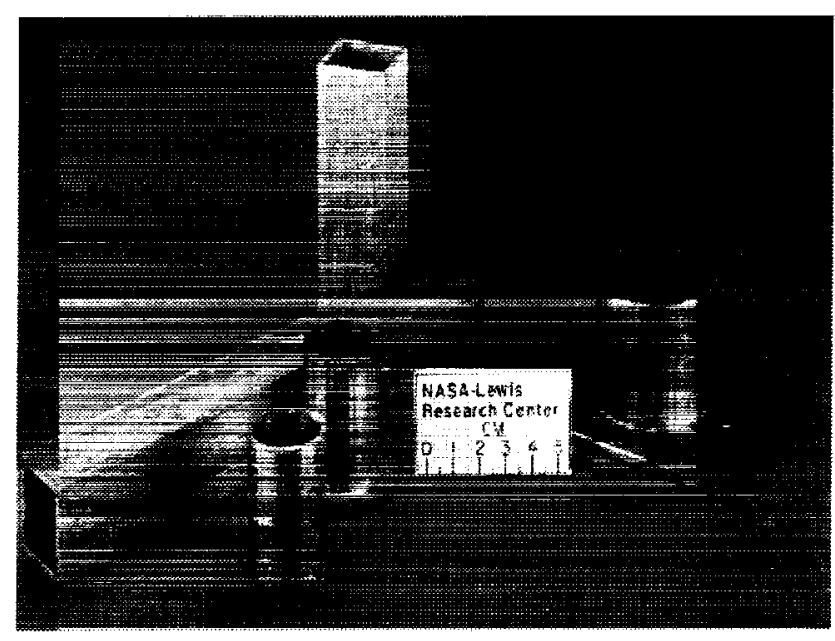

Figure 1.-Photograph showing components fabricated by joining fiber reinforced silicon carbide matrix composite sub-elements.

A variety of silicon carbide-based ceramics and fiber-reinforced composites have been joined using this approach (refs. 5 to 12). Figure 1 is a photograph showing components fabricated by joining fiber-reinforced silicon carbide matrix composite sub-elements using ARCJoinT.

\section{JOINT DESIGN ISSUES}

Among the various alternatives available to overcome the limitations of the many fabrication technologies for the manufacture of large CMC components and structures of complex shape, the joining of smaller components with simple geometry appears to be the most promising and practical. Although the use of joints for the manufacture of structural components will simplify the manufacturing process, it introduces additional complexities for the design and analysis of these structures. In addition to the approaches that are under consideration for the design, analysis and manufacture of single CMC parts, it will be essential to develop standardized tests, design methodologies, and life-prediction analyzes for structures incorporating joints of these materials. Although substantial work has been conducted in the design and characterization of joints of fiber-reinforced polymer matrix composites and metals, comparable work for $\mathrm{CMCs}$ is limited because these materials are relatively new. For the ceramic-metal systems, various joint designs and design criteria have been established (refs. 1 to 3 ). These designs accommodate a number of factors including stresses and stress distribution in the joint regions, which are dependent upon joint configuration and chemical and thermal property mismatch between the joint and substrate materials. A wide variety of test methods (refs. 1 to 3 ) have also been used to determine the tensile strength, peel strength, flexural strength, shear strength, and compressive strength of ceramic-metal joints. Although, many of these tests could be implemented for the evaluation of joints of CMCs, work still will be needed to standardize these tests in order to address issues that are unique to ceramics and ceramic matrix composites.

Design considerations for ceramics and ceramic matrix composites are typically more complicated than for other conventional engineering materials in view of the fact that in the majority of the cases these materials will be used at elevated temperatures, under stress, in aggressive environments, and for very long periods of time. Ideally, it would be desirable to evaluate the strength and reliability of joints under states of stress/strain that are comparable to those that will be found in the intended application and more often than not, service conditions involve multiaxial states of stress.

One approach for the design and analysis of reliability and durability of joints of CMCs that takes into account the multiaxial state of stress/strain that these joint specimens will face consists of using failure maps. Figure 2 shows a schematic of a failure map for loading conditions associated with a bi-axial state of stress (i.e., combinations of shear and normal stresses) that are often found in the application of joints. This state of stress would be encountered for example, when joining tubes to a manifold in a heat exchanger (fig. 3). For the purpose of designing joints of CMCs, it would be desirable to develop failure envelopes as a function of temperature and environment. Since most 


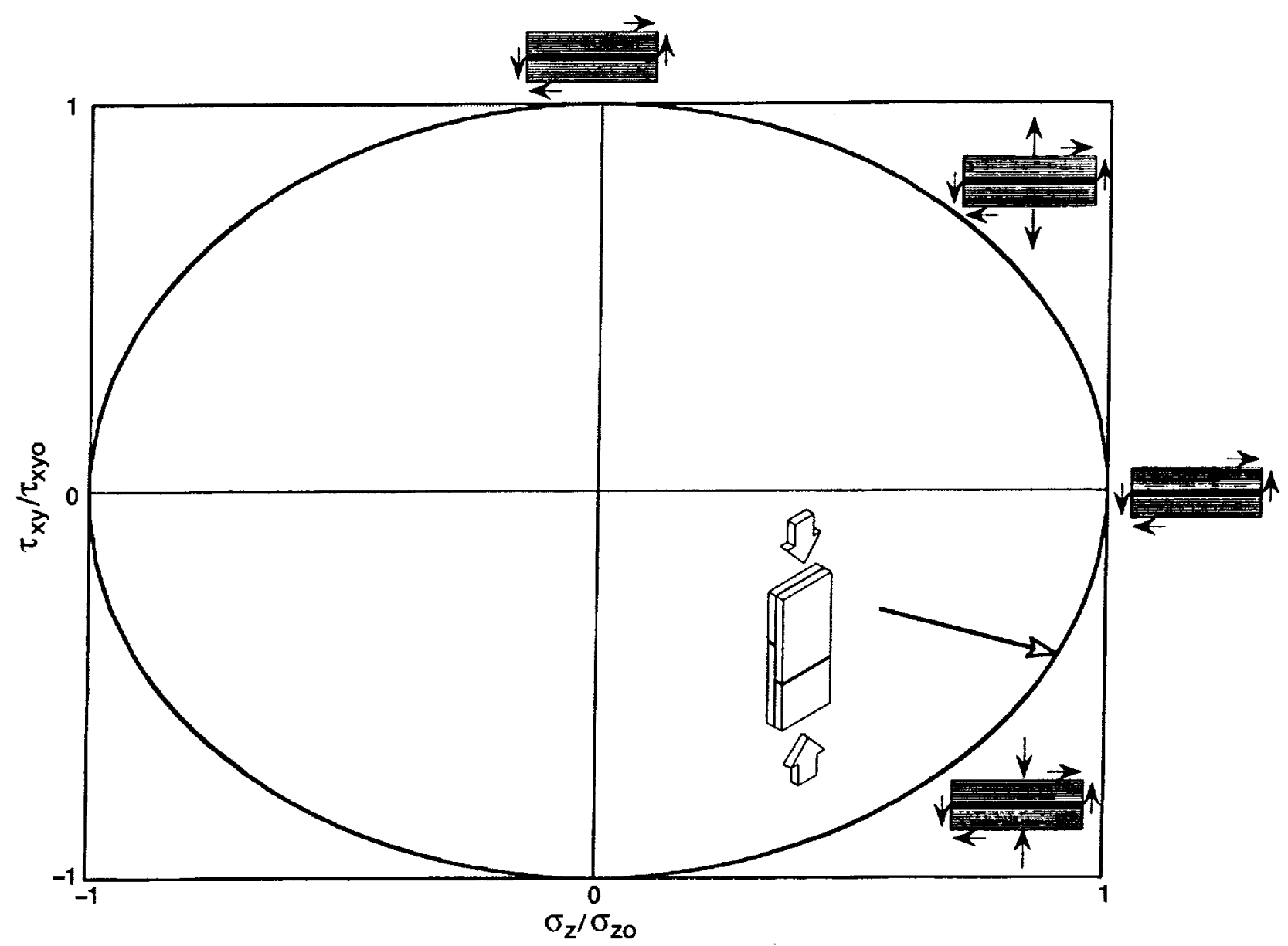

Figure 2.-Schematic of a joint design map where the shear and normal stresses have been normalized by the virgin isothermal joint strengths. The envelope defines the strength of the joint.

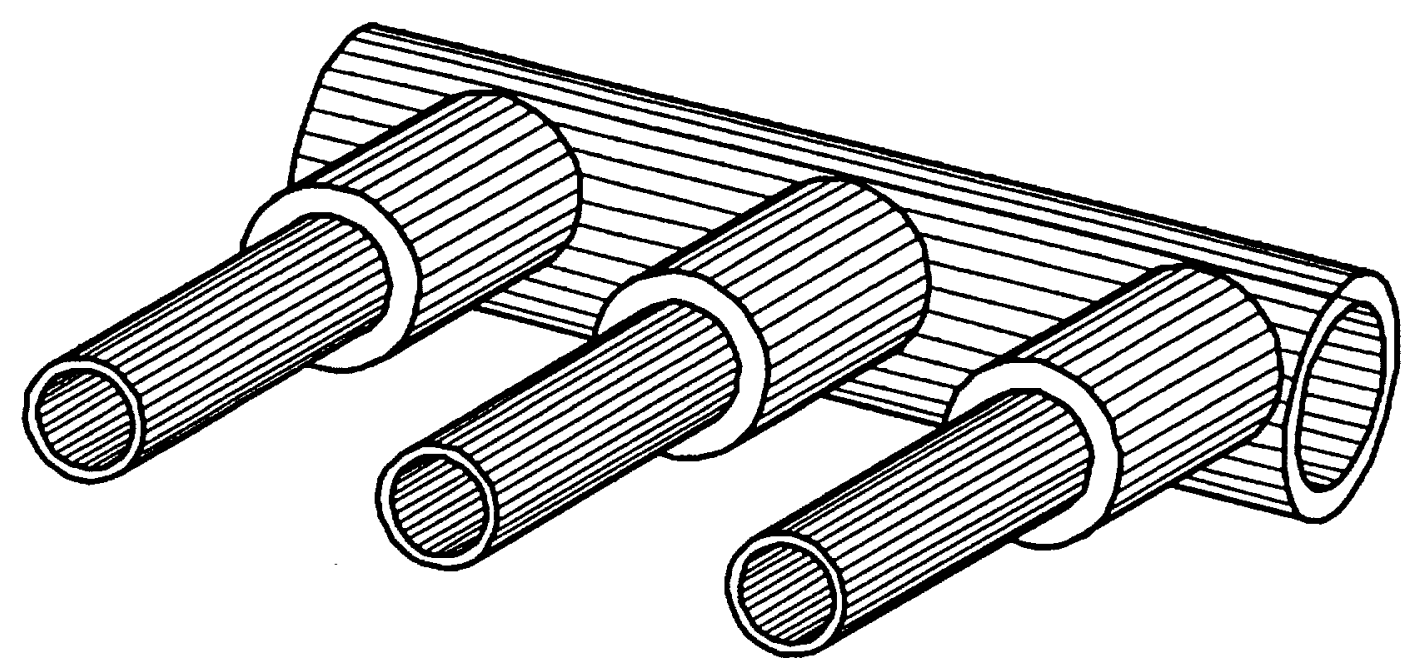

Figure 3.-Schematic of tubes joined to a manifold where stresses in the joint regions involve multiaxial states of stress. (e.g., normal plus shear stresses). 


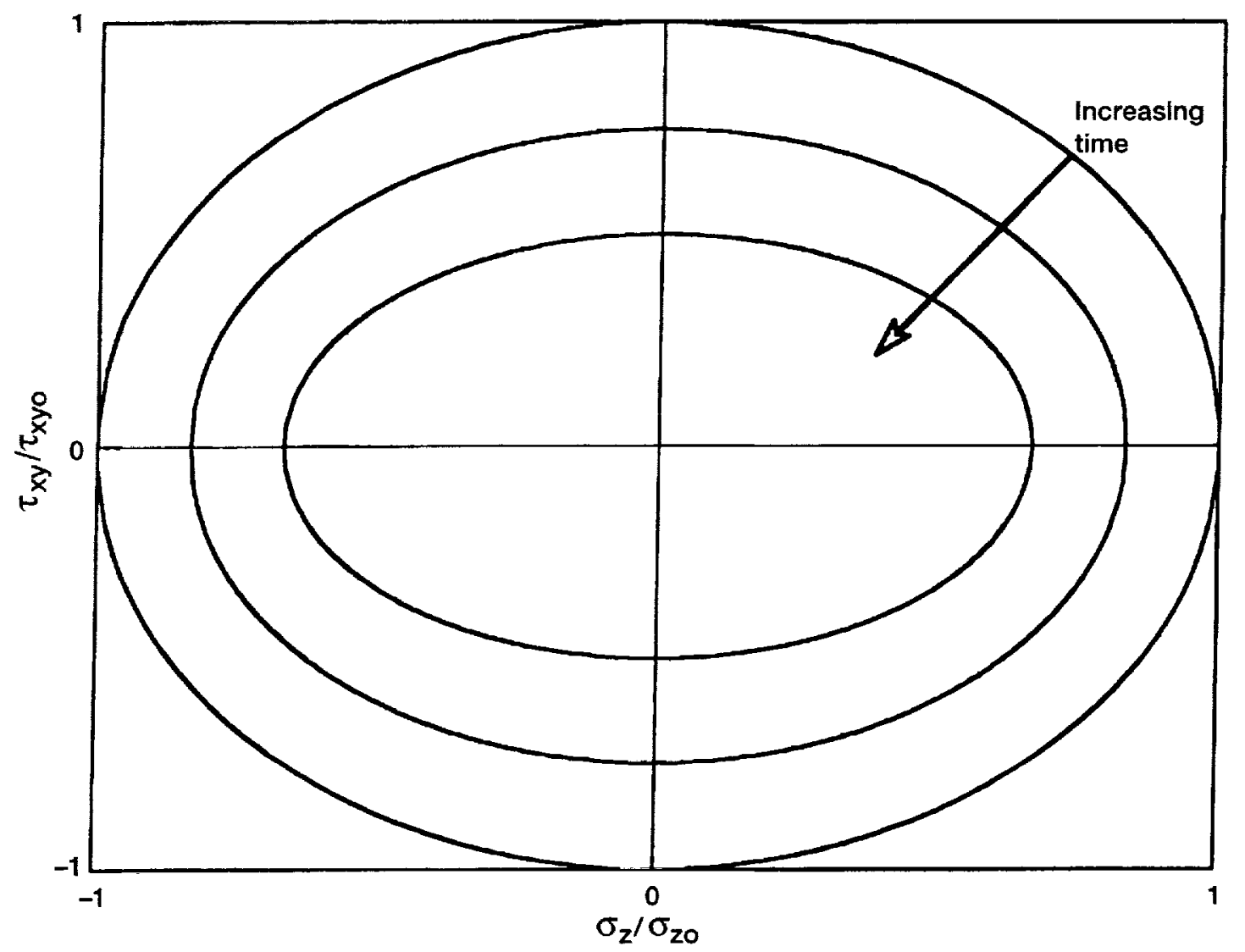

Figure 4.-Schematic of a joint design map where the design envelope shrinks due to degradation of strength with time.

of the envisioned applications of CMCs, specially those for the energy industries, have service lives that are measured in several thousands of hours, it will also be necessary to generate information about how failure envelopes evolve as a function of time. Considering the aggressive service conditions that are associated with most of the envisioned applications of $\mathrm{CMCs}$, it is likely that the strength of the joints will be controlled by degradation mechanisms that include: slow crack growth, stress rupture, creep, and oxidation/corrosion. Therefore, in their simplest form, (i.e., for applications where stresses would remain constant with time) failure maps will be defined by failure envelopes that shrink with time as a result of strength degradation. Figure 4 illustrates this idea.

In this paper, experimental results are presented for the virgin shear strength and the shear stress rupture behavior of joined silicon carbide (CG-Nicalon ${ }^{\mathrm{TM}}$ ) fiber-reinforced CVI SiC composites. The shear strength of the joints was determined by the compression of double-notched specimens. Although, there is a consensus on the lack of a good test for determining the shear strength of joined composites, the compression of double-notched specimens is a popular test because it requires relatively small samples ${ }^{\mathrm{I}}$ and it is relatively simple to conduct. In this test, shear failure is induced between two notches that are antisymmetrically located on opposite sides of the specimen at an equal distance from the mid plane. The drawback of this test method is that because interlaminar shear failure is induced by the stress concentration at the root of the notches, the shear stress distribution between the notches is not uniform. Furthermore, in addition to shear stresses in the gauge section of the specimen, normal compressive stresses are also induced in this region. Therefore, in reference to the diagram in figure 2, data generated by the compression of double-notched specimens would lay in the third quadrant of the failure map in figure 2 . This test method was recently standardized by ASTM for the determination of the interlaminar shear strength of one- and two-dimensional continuous fiber-reinforced ceramic matrix composites at room temperature and elevated temperatures (ASTM C1292, ASTM C1425) and seems appropriate for the determination of the shear strength of joints (refs. 13 to 15). Figure 5 shows the schematic of the double-notched joint specimen.

\footnotetext{
'Because monolithic ceramics and ceramic matrix composites exhibit volumetric dependence of strength, it will be necessary to appropriately scale the results from the evaluation of joints using "small" specimens, according to the specific application.
} 


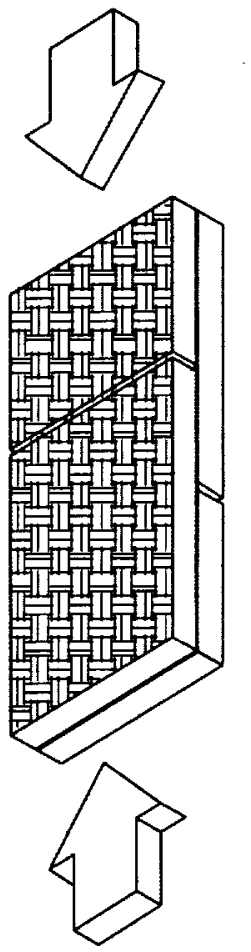

Figure 5.-Schematic of double-notched shear specimen.

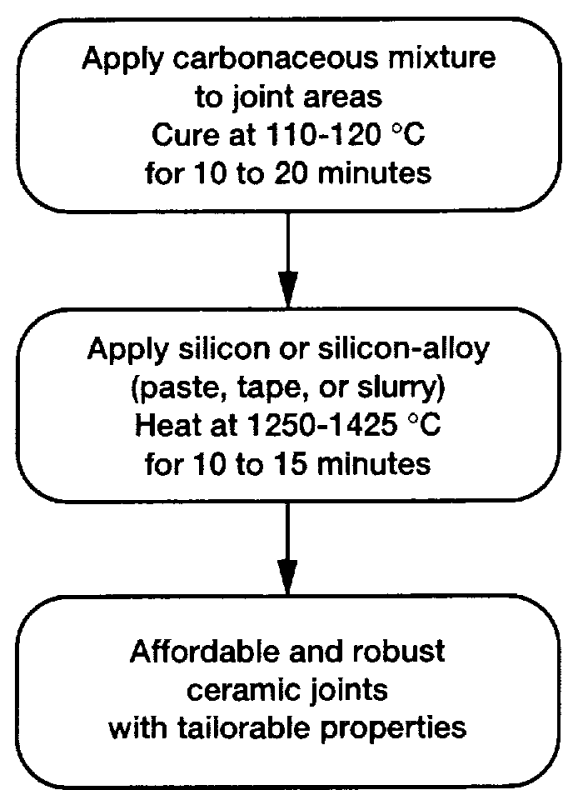

Figure 6.-Schematic of the process for joining of fiber reinforced silicon carbide matrix composites.

\section{FABRICATION}

The composites used in this study were obtained from Honeywell Advanced Composites, Inc., Newark, Delaware. These composites were fabricated with plain weave fabric of $\mathrm{SiC}$ (CG Nicalon ${ }^{\mathrm{TM}}$ ) fibers ${ }^{2}$ with a thin pyrolytic carbon fiber coating. The $\mathrm{SiC}$ matrix was deposited via chemical vapor infiltration and the matrix contained an oxidation-resistance "enhancement" of proprietary composition. The fiber volume fraction was 44 percent. As-fabricated specimen surfaces were cleaned in acetone and dried before joining. A flow diagram of the affordable, robust ceramic joining technology (ARCJoinT) is given in figure 6 . The joining process (refs. 7,11,12) begins with the application of a carbonaceous mixture in the joint area and a curing step at 110 to $120^{\circ} \mathrm{C}$ for 10 to 20 min while holding the items to be joined in a fixture thus fastening the pieces together. Then, a silicon-titanium alloy in paste form was applied around the joint region and heated to $1360^{\circ} \mathrm{C}$ for $15 \mathrm{~min}$. The molten silicon-titanium alloy reacts with carbon to form silicon carbide with controllable amounts of silicon and titanium disilicide phases. By controlling the consistency of the carbonaceous paste and the magnitude of the applied force with the fixture, the thickness of the joint can thus be controlled. A wide variety of silicon carbide-based ceramics and ceramic matrix composites, consisting of different sizes and shapes, have been joined using this technology (fig. 1).

After the specimens were joined, double-notched specimens were machined to conform to the specimen geometry in Fig. 5 (6 mm wide, $22 \mathrm{~mm}$ long, $6.15 \mathrm{~mm}$ thick) using a diamond-impregnated wheel. The notches were machined in several passes with a removal rate of $2.5 \mu \mathrm{m} /$ pass using a $0.5 \mathrm{~mm}$ thick wheel. The final notch separation was $4.0 \pm 0.05 \mathrm{~mm}$. The compression tests of double-notched specimens were conducted in ambient air at temperatures of 20,1000 , and $1200^{\circ} \mathrm{C}$ using a pneumatically actuated system, a box furnace with $\mathrm{SiC}$ heating elements and a $\mathrm{SiC}$ fixture. Figure 7 shows a schematic of the fixture used for the tests. The shear test fixture, which was machined from sintered silicon carbide (Hexoloy-SA SiC), consists of two semi-cylindrical sections used to center the specimen, two pistons, one sleeve and an aligning disk. Two layers of ceramic paper were used to accommodate nonuniformities in the thickness of the specimen and dimensional changes that result from thermal expansion. To minimize Hertzian contacts and nonuniform loading, the parallelism between the ends of the specimen were maintained within $50 \mu \mathrm{m}$.

${ }^{2}$ Nippon Carbon Co.. Japan. 


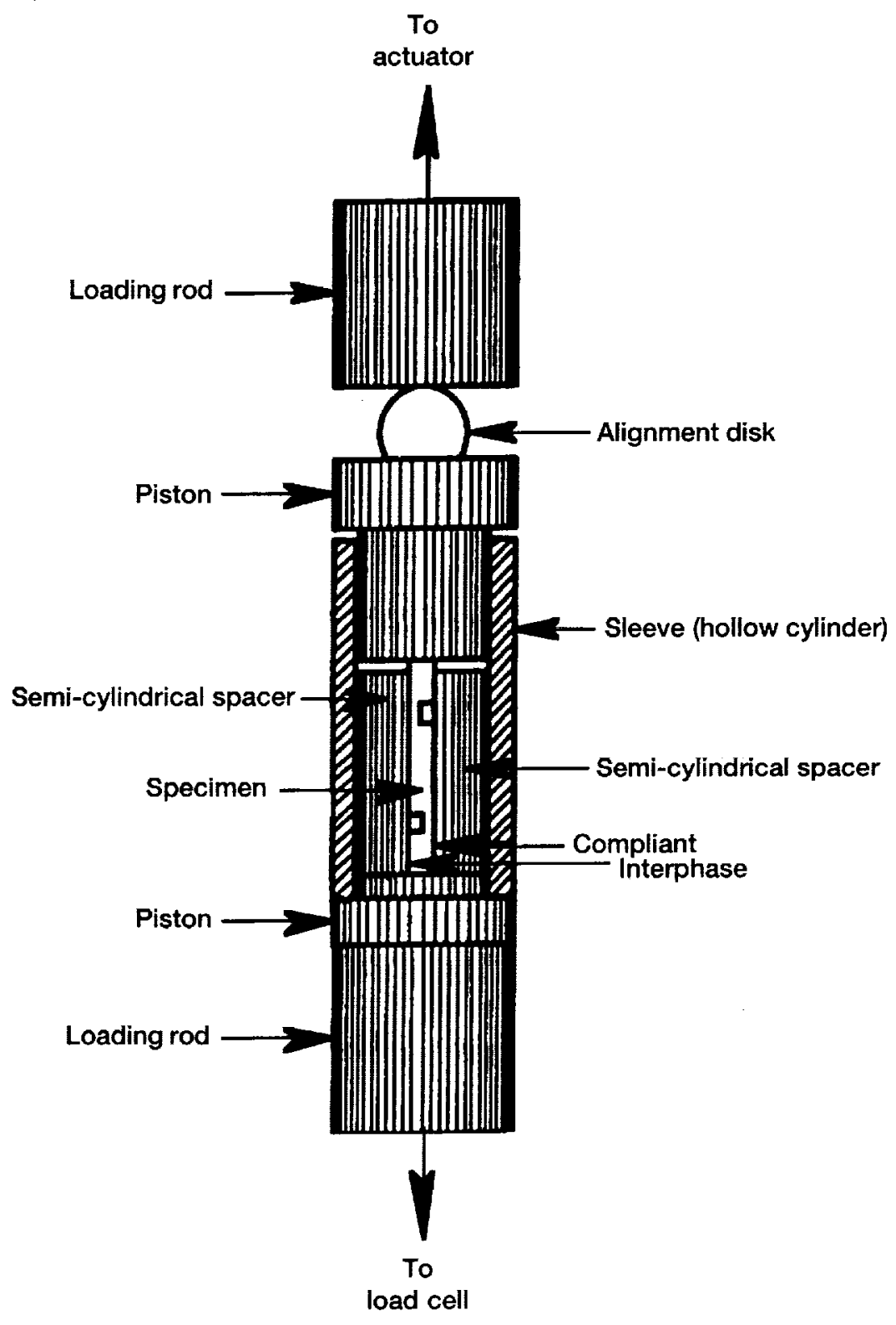

Figure 7.-Schematic of fixture used for the compression of double-notched specimens at elevated temperatures.

For the tests at elevated temperatures, the specimens were heated to the test temperature at a rate $60{ }^{\circ} \mathrm{C} / \mathrm{min}$, followed by a soak period of $15 \mathrm{~min}$ to allow for thermal equilibrium. Temperature was monitored and controlled using a type " $\mathrm{S}$ " thermocouple which was positioned next to the fixture. The tests were conducted at a constant loading rate of $50 \mathrm{~N} / \mathrm{s}$.

Shear stress-rupture tests were also conducted at $1200^{\circ} \mathrm{C}$ for stresses of 35 and $17.5 \mathrm{MPa}$. The specimens were heated to $1200^{\circ} \mathrm{C}$ at a rate of $60^{\circ} \mathrm{C} / \mathrm{min}$ followed by a soak period of $15 \mathrm{~min}$. Then the specimens were mechanically loaded to the test stress at a rate of $50 \mathrm{~N} / \mathrm{s}$ and the load was maintained constant until the specimens failed and the time to failure was recorded. 

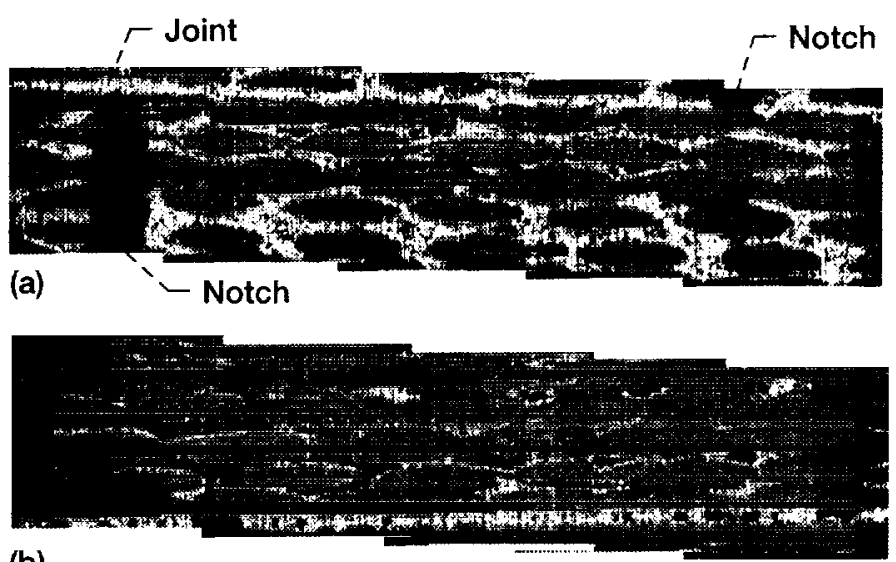

(b)

Figure 8.-CG-Nicalon TM/SiC (CVI)//CG-Nicalon ${ }^{T M} / \mathrm{SiC}(\mathrm{CVI})$ double-notched joint specimen. (a) and (b): Photographs of double-notched joint specimens.

\section{RESULTS AND DISCUSSION}

Photomacrographs of two joined specimens with notches are shown in figures 8(a) and (b). Note that the composite material contains a large amount of porosity in the interlaminar regions, which is characteristic of most composite materials synthesized by chemical vapor infiltration. It was also observed that the joint region contained porous regions (fig. $8(\mathrm{~b})$ ).

Figure 9 shows typical curves of the average shear stress versus cross-head displacement obtained from the monotonic testing of specimens at 1000 and $1200^{\circ} \mathrm{C}$. The average shear stress was calculated as follows

$$
\tau=\frac{P}{w h}
$$

where $P$ is the applied compressive load, $w$ is the width of the specimen and $h$ is the distance between the notches. Note that the curves in figure 9 are increasingly stiffer up to the peak load which suggests that there is no crack growth prior to failure. Also note that the compliance of the specimens (as determined from the instantaneous slope of the curves) increased with test temperature.

Analysis of the specimens after the tests revealed that the specimens failed within the joint in a cohesive mode along a plane in between the notches. Micrographic examination of the fracture surfaces showed that some regions of the joint were not fully infiltrated, which was consistent with analysis of the edges of the specimen (fig. 8). Figure 10 shows a optical micrograph of the fracture plane for a specimen tested at $1200^{\circ} \mathrm{C}$.

Figure 11 summarizes the mechanical test results and indicates that the shear strength of the joints decreases with temperature from $92 \mathrm{MPa}$ at ambient temperature to $71 \mathrm{MPa}$ at $1200^{\circ} \mathrm{C}$. The results from the shear stressrupture tests are summarized in figure 12. It was found that the shear strength of the joints drops rapidly with time from $71 \mathrm{MPa}$, which is the "virgin" monotonic strength of the joints to $17.5 \mathrm{MPa}$ after $14.3 \mathrm{hr}$. These results are important because they revealed the weakness (i.e., rapid loss of strength with time) of a joint system that would have been considered robust based only on its virgin strength. Although additional work is still needed to identify the mechanisms responsible for the rapid loss of strength of these joints, it is well known that the formation and coalescence of cavities in siliconized silicon carbide lead to the formation of cracks, and that cavity growth occurs very rapidly in siliconized silicon carbide (ref. 16). Therefore, the combination of high localized stresses around pores and notches and formation and coalescence of cavities are believed to be responsible for the rapid loss of strength exhibited by the joint material. 


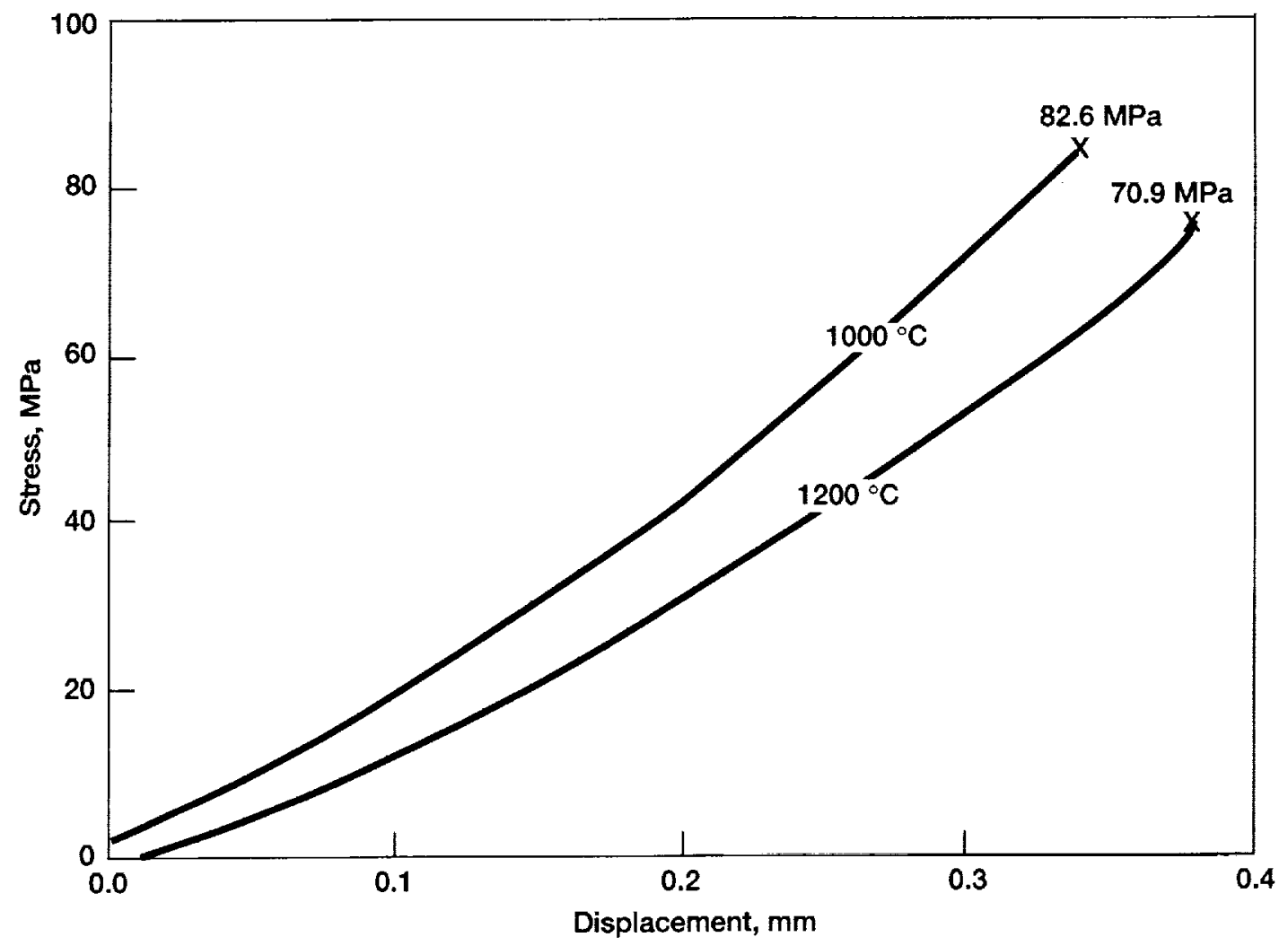

Figure 9.-Typical shear stress versus cross-head displacement curves obtained from the compression of double-notched joint specimens at high temperatures.

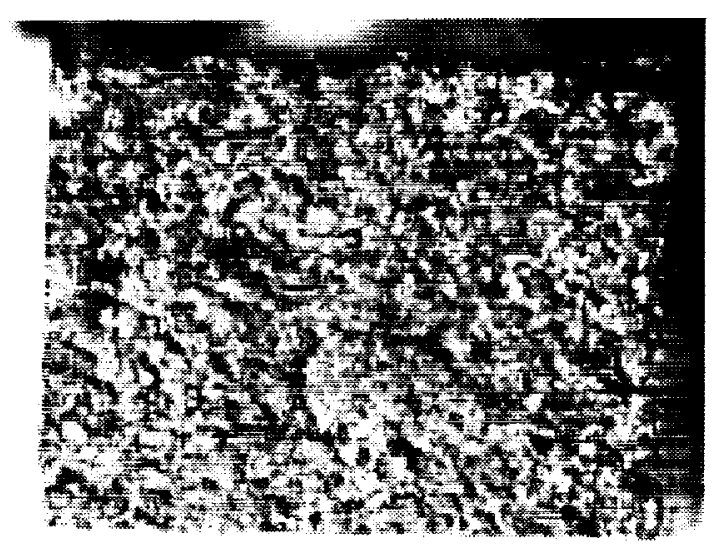

Figure 10.-Optical micrograph of fracture surfaces of joined $\mathrm{CVI} \mathrm{SiC} / \mathrm{SiC}$ composites tested at $1200^{\circ} \mathrm{C}$. 


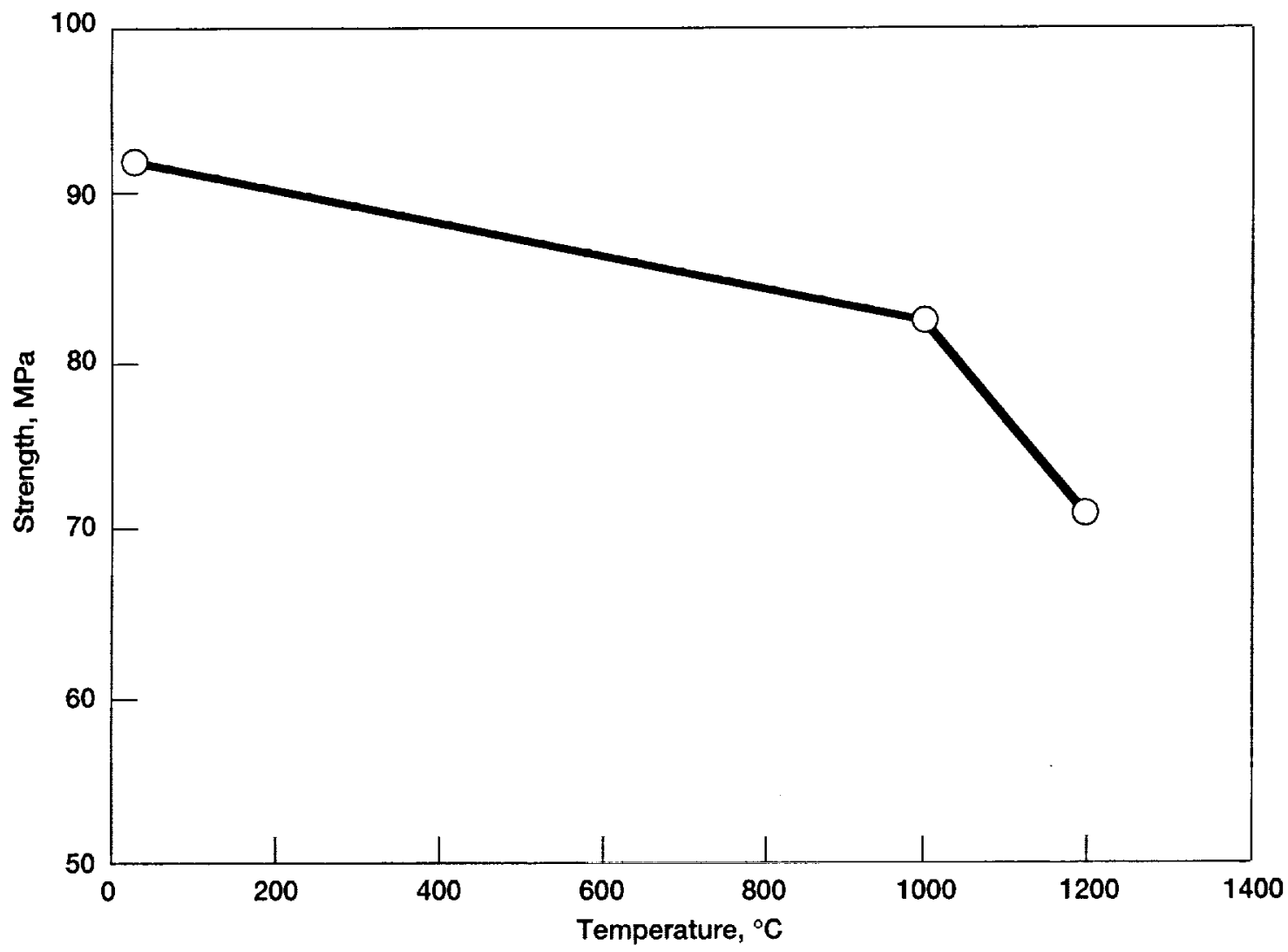

Figure 11.-Temperature dependence of apparent shear strength for joined SiC (CG-Nicalon ${ }^{T M}$ )/C/CVI-SiC composites.

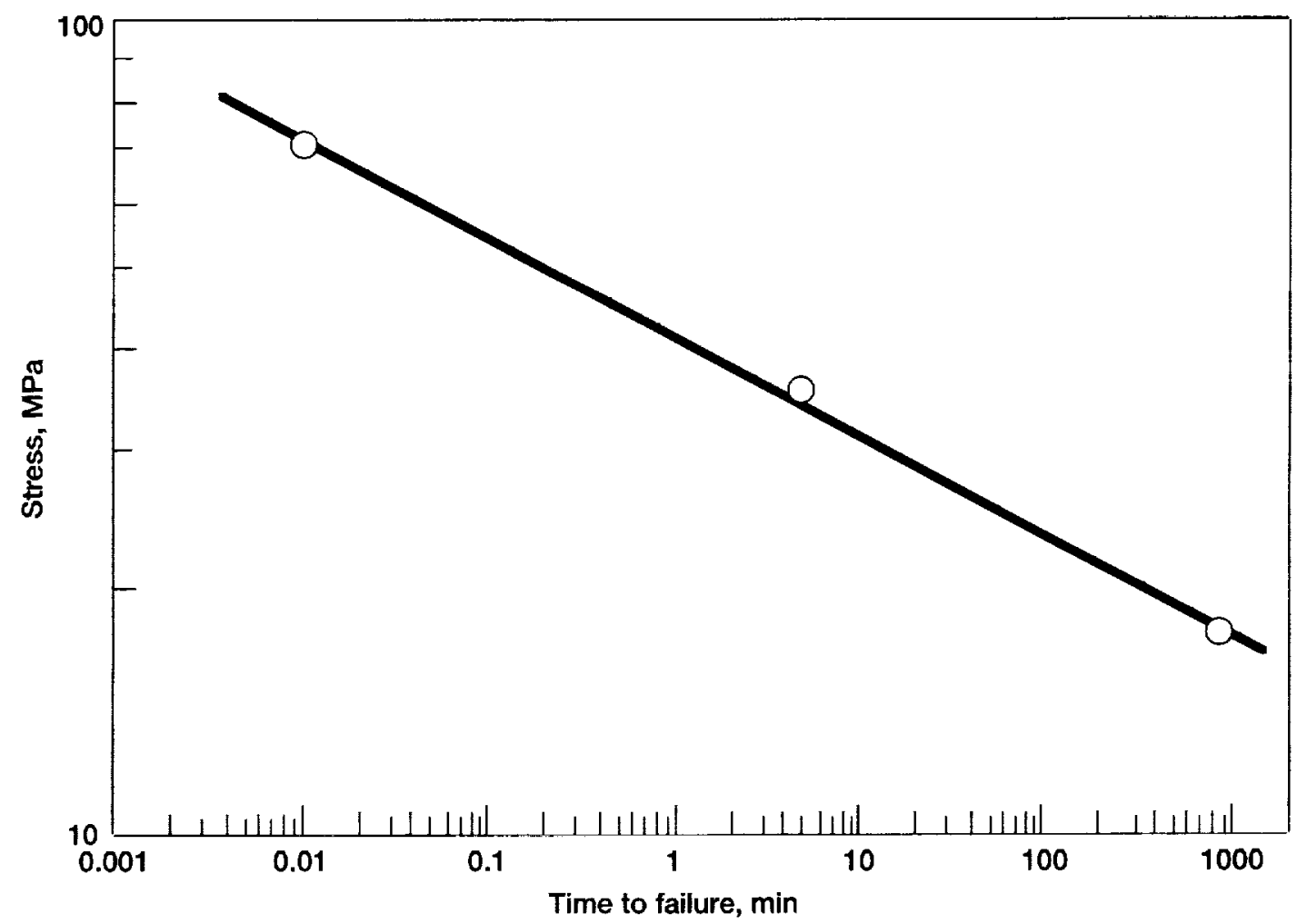

Figure 12.-Results from shear stress-rupture evaluation of joints at $1200^{\circ} \mathrm{C}$. The data point at the shortest time corresponds to the "virgin" shear strength of the joints. 


\section{CONCLUSIONS}

The shear strength and stress rupture behavior of joints of SiC (CG-Nicalon ${ }^{\mathrm{TM}}$ ) fiber- reinforced CVI-SiC matrix composites were determined by the compression of double-notched specimens. The joints were obtained using ARCJoin T and consisted of $\mathrm{SiC}$ plus small amounts of free silicon and titanium disilicide. From the evaluation of specimens with a notch separation of $4 \mathrm{~mm}$, it was found that the apparent shear strength of the joints decreased from $92 \mathrm{MPa}$ at room temperature to $71 \mathrm{MPa}$ at $1200^{\circ} \mathrm{C}$. However, it was found from stress-rupture testing in air at $1200^{\circ} \mathrm{C}$ that the strength of the joints decreased rapidly with time from a "virgin" monotonic strength of 71 to $17.5 \mathrm{MPa}$ after $14.3 \mathrm{hr}$.

The conduct of extensive systematic tests of this nature (as a function of stress, time, temperature and environment) is required to provide sufficient information for the generation of failure maps, and the kinetics of loss of strength. This information along with microstructural, chemical and fractographic examination will help identify the mechanisms responsible for the loss of strength and provide guidance for the optimization of the joints.

\section{REFERENCES}

1. R.W. Messler, Jr., "Joining of Advanced Materials," Butterworth-Heinemann, Boston, MA (1993).

2. M. M. Schwartz, "Joining of Composite Matrix Materials," ASM International, Materials Park, OH (1994).

3. J.M. Fragomeni and S.K. El-Rahaiby, "Review of Ceramic Joining Technology," Rept. No. 9, Ceramic Information Analysis Center, Purdue University, Indiana (1995).

4. W. Krenkel, T. Henke, and N. Mason, Key Engineering Materials, 127-131 (1997), pp. 313-320.

5. M. Singh, J.D. Kiser, and S.C. Farmer, Ceram. Eng. and Sci. Proceedings, 18, 3 (1997), pp. 161-166.

6. M. Singh and J.D. Kiser, "Physics and Process Modeling and Propulsion R\&T Conference," NASA CP-10193 (1997) 5:1-10.

7. M. Singh, Scripta Materialia, 34, 8 (1997), pp. 1151-1154.

8. M. Singh, Industrial Heating, 9 (1997), pp. 91-93.

9. M. Singh, J. Mater. Sci. Letters, 17, 6 (1998), 459-461.

10. M. Singh, J. Mater. Sci., 33 (1998), pp. 5781-5787.

11. M. Singh, Advanced Materials and Processes, 10 (1998), pp. 89-90.

12. M. Singh, "Key Engineering Materials," 164 (1999) pp. 415-420.

13. ASTM C 1292, "Test method for shear strength of continuous fiber-reinforced advanced ceramics at ambient temperatures," American Society for Testing and Materials, Conshohocken, PA (1996).

14. E. Lara-Curzio and M.K. Ferber, "Shear Strength of Continuous Fiber Reinforced Ceramic Composites," in Thermal and Mechanical Test Methods and Behavior of Continuous Fiber Ceramic Composites, ASTM STP 1309. M.G. Jenkins, S.T. Gonczy, E. Lara-Curzio, N.E. Ashbaugh and L.P. Zawada Eds., American Society for Testing and Materials, Philadelphia, PA (1996).

15. M. Singh and E. Lara Curzio, unpublished work (2000).

16. D.F. Carroll and R.E. Tressler, J. Am. Ceram. Soc., 71, 6, (1988) pp. 472-477. 


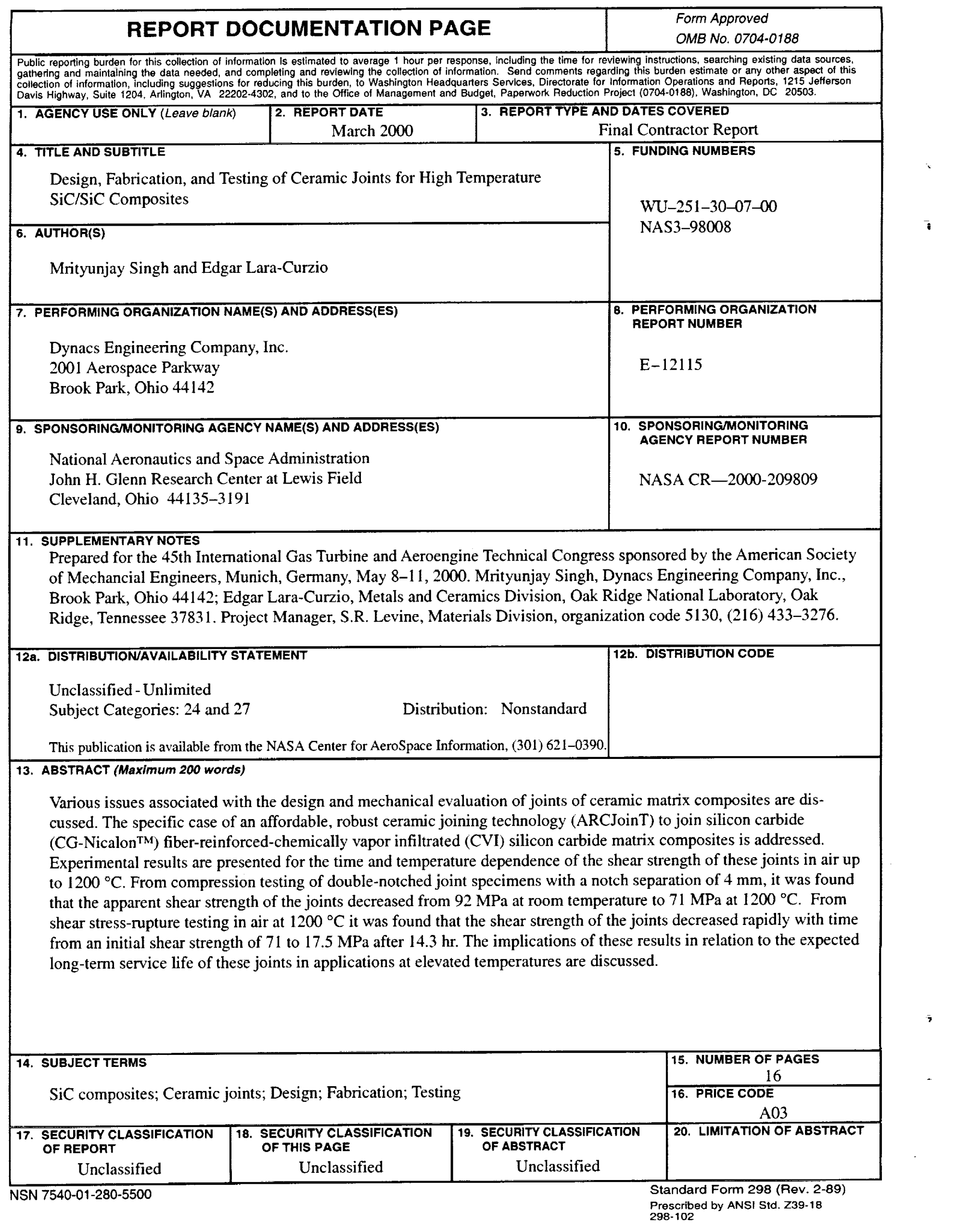

